\title{
Alternate Healthcare Systems and Their Utilization with Special Reference to Kanniyakumari and Tirunelveli Districts of Tamil Nadu, India
}

\author{
J. Cyril Kanmony \\ Emeritus Professor of Economics, Scott Christian College (Autonomous), Nagercoil, \\ Kanniyakumari District, India cyrilkanmony@ymail.com
}

\begin{abstract}
In India, the modern medicine (Allopathy) has almost replaced the Traditional system of medicines (AYUSH) and the private healthcare sector has grown by leaps and bounds at the cost of the public sector. This study is conducted mainly to analyse the standout features of different healthcare systems and the factors that influence their usage and to suggest ways and means of strengthening them. Among the two systems of medicine, Allopathy is ranked first, the most utilized system of healthcare, in both the districts and among the two major healthcare providers, the private sector is much preferred to the public sector. The utilization of a service is highly influenced by the income and the education of the respondents. Allopathy is preferred as it provides fast relief from illness while AYUSH is preferred as it has zero side effects. Public hospitals are preferred as medicines are free and private hospitals are preferred as doctors' care for patients is excellent. Location and distance also have some influence on the preference for the healthcare providers. The main reason for the poor performance of public healthcare sector, which is in a dilapidated condition, is the utter negligence of it by governments.
\end{abstract}

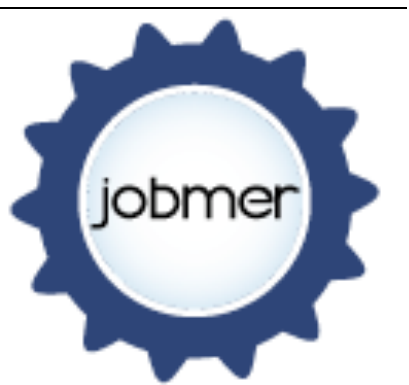

Journal of Business

Management and Economic Research

Vol.2, Issue.4, 2018

pp.11-26

Doi: 10.29226/TR1001.2018.27

Keywords: Alternate Healthcare Systems 


\section{Introduction}

There are two healthcare systems, Allopathy, which is called the modern or the English and AYUSH (Ayurveda, Yoga \& Naturopathy, Unani, Siddha and Homeopathy), which is called the Traditional or the Indian. The modern system of healthcare pervades every nook and cranny of the world and in India; it has almost replaced the Indian system of medicine. These systems of medicine are provided by both public sector and private sector institutions. Public sector ownership is divided between central and state governments, and municipal and local governments. In India, due to malfunctioning or non-functioning of the public sector, the private sector has grown in leaps and bounds. At the time of independence, the share of modern medical care provided by private sector was only 8 per cent. Now, 80 per cent of all out-patient care and 60 per cent of all in-patient care is provided by it (Ministry of Health and Family Welfare 2010 in Nandraj 2012). Thus, vast changes have occurred in the healthcare systems functioning in the world. Utilization of a system of healthcare and of a service provider is influenced by many factors. As it is the fountain duty of researchers to highlight different factors that influence the utilization of healthcare systems and healthcare service providers, this article aims at attaining this broad objective.

\section{Objectives}

The specific objectives of this study are:

1. To highlight factors those influence the usage of healthcare systems.

2. To understand to what extent allopathy is preferred to the Indian healthcare system.

3. To know why people approach private healthcare providers rather than public healthcare providers.

4. To find out the reasons why the public healthcare sector fails to attract people though where healthcare services are provided free of cost.

5. To suggest ways and means to strengthen the various healthcare systems, particularly the public healthcare delivery system.

\section{Hypotheses}

The hypotheses framed for testing the reliability of data are:

1. There is no strong preference to a particular healthcare system.

2. Income has no role play in the preference for a healthcare system and a healthcare provider.

3. The preference for a healthcare system and a healthcare provider is not influenced in any way by education of the respondents.

4. The usage of a healthcare provider is not influenced by the distance of a healthcare institution.

\section{Review of Literature}

There are only very few studies on the two systems of healthcare but a number of studies on the preference of individuals to a particular healthcare institution. It is viewed that people prefer private hospitals to public hospitals due to poor performance of public sector healthcare institutions and the reasons for the poor performance is very low public spending. Sundararaman et al (2016) report that the growth of the central government's spending in real terms on public health between 2004-'05 and 2009-'10 was 13.65 per cent, but it plummeted to 0.31 per cent between 2010-'11 and 2014-'15. All these have immediate adverse effect on the availability and quality of public healthcare services and have forced many people to go to 
private hospitals and this has even resulted in impoverishment of many families. This was endorsed by Nagpal (2014); Bansod and Sarang (2014) Jackson et al (2013); Prasad and Raghavendra (2012); Reddy (2012); Husain (2011); Baru et al (2010); Meeta and Rajivlochan (2010); Kanmony in Kanmony (Ed) (2009); Murty in Lahiri (Ed) (2006); Preker in Prekar and John (Ed) (2005); Rajagopal (2004); Banerjee et al (2004).

Varshney and Aparna (2011) point out that the high cost of modern medicine compelled people to switch over to herbal medicine as nowadays it is gaining importance. According to Husain (2011) AYUSH plays a pivotal role in delivering healthcare services. As there is manpower shortage in rural areas, the NHRM seeks to revitalise AYUSH practitioners as the alternative for allopathic medical staff for certain kinds of chronic ailments and digestion and related illnesses. Prasad and Cyril in Kumar J. V et al (ed) (2010) observe that the Traditional systems of medicine are undoubtedly emerging as very close substitutes to the modern medicines and India has a large number of AYUSH hospitals. Hence it is the utmost necessity of researchers to find out the causes for this state of affairs.

\section{Methodology}

The present study is mainly based on primary data. The primary data have been collected from 400 households belonging to two districts of south Tamil Nadu, - Kanniyakumari and Tirunelveli. A village panchayat has been selected from each of the four taluks of Kanniyakumari district and, as there are 13 taluks in Tirunelveli district first of all four taluks were selected, then a village panchayat has been selected from each taluk at random. Thus, four village panchayats have been selected from each district and from each village panchayat, 50 households have been selected at random - first five wards then 10 households have been chosen from each ward. In total, 400 sample households have been selected for an intensive study by following multi-stage sampling procedure. With the help of a scientifically prepared schedule, necessary information has been collected from the selected households. With the help suitable tools, data have been processed, analysed and presented.

\section{DATA ANALYSIS}

This section deals with the analysis of data by applying the most appropriate tools of analysis. Garrett Ranking and correlation and Regression analysis are the most commonly used analytical tools. In this article, all these are made use of to make the study scientific.

\section{Utilization of Healthcare Systems}

People of ill-health may take either self-medication or approach doctors for medicine. To get medicine they may approach either Allopathy doctors or AYUSH doctors. The details regarding the usage of the two healthcare systems in different regions of Kanniyakumari district are presented in table 1.

TABLE - 1:Usage of Healthcare Systems in Kanniyakumari

\begin{tabular}{|l|c|c|c|}
\hline \multirow{2}{*}{ Area of the Respondents } & \multicolumn{2}{c|}{ No. of Respondents } & \multirow{2}{*}{ Total } \\
\cline { 2 - 3 } & Allopathy & Traditional & \\
\hline Vilavancode & 21 & 29 & 50 \\
\hline Thovalai & 41 & 9 & 50 \\
\hline Kalkulam & 48 & 2 & 50 \\
\hline Agasteeswaram & 33 & 17 & 50 \\
\hline Total & 143 & 57 & 200 \\
\hline
\end{tabular}

Source: Primary Data 
From the above table, it is clear that the utilization of the Traditional system of medicine is the maximum in Vilavancode taluk with 29 respondents using it. In other taluks, it is very limited in number. In Tirunelveli district, only 46 respondents have utilized the Traditional system of medicines and all others used Allopathy. These details about Tirunelveli are available in table 2.

TABLE - 2: Usage of Healthcare System in Tirunelveli

\begin{tabular}{|l|c|c|c|}
\hline \multirow{2}{*}{ Area of The Respondents } & \multicolumn{2}{|c|}{ No. of Respondents } & \multirow{2}{*}{ Total } \\
\cline { 2 - 3 } & Allopathy & Traditional & \\
\hline Sivagiri & 46 & 4 & 50 \\
\hline Sangarankovil & 32 & 18 & 50 \\
\hline Alangulam & 40 & 10 & 50 \\
\hline Nanguneri & 36 & 14 & 50 \\
\hline Total & 154 & 46 & 200 \\
\hline
\end{tabular}

Source: Primary Data

The preference for a particular type of medical system depends on many factors such as the cost of treatment, the period taken for curing and the financial and educational soundness of persons and so on. The preferences given to different systems of healthcare by the respondents are ranked by applying the Garrett Ranking method and are presented in the following table.

TABLE - 3: Ranking of Healthcare Systems by the Respondents

\begin{tabular}{|l|c|c|c|c|}
\hline \multirow{2}{*}{ Systems Districts } & \multicolumn{2}{|c|}{ Kanniyakumari } & \multicolumn{2}{c|}{ Tirunelveli } \\
\cline { 2 - 5 } & Score & Rank & Score & Rank \\
\hline Allopathy & 78.52 & 1 & 79 & 1 \\
\hline Ayurveda & 55.45 & 4 & 54.175 & 4 \\
\hline Yoga \& Naturopathy & 40.17 & 5 & 38.025 & 5 \\
\hline Unani & 35.04 & 6 & 36.76 & 6 \\
\hline Siddha & 59.24 & 2 & 59.055 & 2 \\
\hline Homeopathy & 58.72 & 3 & 58.085 & 3 \\
\hline
\end{tabular}

Source: Calculated from Primary Data

It is noticeable from the above table that Allopathy occupies the first place in both the districts with a score of 79 . The second rank goes to siddha with a score of 59.24. It is followed by homeopathy, ayurveda, yoga and naturopathy and unani in order in both the districts. It means that among the different healthcare systems, Allopathy is the most preferred system of medical care. From the above three tables, it is easy to infer that the first hypothesis that 'there is no strong preference to a particular healthcare system' is not valid.

However, the number of households using the Indian system is more in Kanniyakumari district than in Tirunelveli district. The reasons for this state of affair may be two. They are: the first is that Ayurveda and Siddha have been in practice in Kanniyakumari district as it was a part of the then Travancore state, the present Kerala state, where these two systems are very popular. The second reason is that Ayurveda and Siddha medicines are available proportionately in more number of hospitals in Kanniyakumari than in Tirunelveli. In Kanniyakumari, there are 34 PHCs with AYUSH medicines against 36 PHCs of the modern medicine while in Tirunelveli, it is only 64 against 92 PHCs with Allopathy facility.

In the demand side, the utilization of a healthcare system is highly influenced by factors such as educational and economic attainment of individuals. Hence, it is worthwhile to discuss these factors one by one. 


\section{Monthly Household Income and the Utilization of Healthcare Systems}

Income decides not only the standard of living and the status of individuals in the society but also their preference for a commodity or service. Usually rich people prefer quality services though their prices are high. The income-wise distribution of the respondents and their utilization of the two systems of medicine and service providers of Kanniyakumari district is given in table 4 . The details for Tirunelveli district are presented in table 5.

TABLE - 4: Incomewise Distribution of the Respondents and Their Utilization in Kanniyakumari

\begin{tabular}{|c|c|c|c|c|c|c|}
\hline $\begin{array}{l}\text { Services } \\
\text { Income (in INR) }\end{array}$ & Allopathy & Traditional & Total & Public & Private & Total \\
\hline$\leq 3000$ & 3 & 1 & 4 & 1 & 3 & 4 \\
\hline $3001-5000$ & 22 & 10 & 32 & 13 & 19 & 32 \\
\hline $5001-7000$ & 23 & 16 & 39 & 18 & 21 & 39 \\
\hline $7001-9000$ & 29 & 15 & 44 & 18 & 26 & 44 \\
\hline $9001-11000$ & 22 & 6 & 28 & 11 & 17 & 28 \\
\hline $11001-13000$ & 6 & 1 & 7 & 2 & 5 & 7 \\
\hline $13001-15000$ & 15 & 2 & 17 & 7 & 10 & 17 \\
\hline $15001-17000$ & 2 & 4 & 6 & 1 & 5 & 6 \\
\hline 17001-19000 & 6 & 0 & 6 & 1 & 5 & 6 \\
\hline 19001-21000 & 3 & 0 & 3 & 0 & 3 & 3 \\
\hline $21001-23000$ & 3 & 0 & 3 & 0 & 3 & 3 \\
\hline $23001-25000$ & 2 & 0 & 2 & 0 & 2 & 2 \\
\hline 25001-27000 & 1 & 0 & 1 & 0 & 1 & 1 \\
\hline$\geq 27001$ & 6 & 2 & 8 & 1 & 7 & 8 \\
\hline Total & 143 & 57 & 200 & 73 & 127 & 200 \\
\hline
\end{tabular}

Source: Primary Data

The average household income in Kanniyakumari is 10,349.34 INR and in Tirunelveli, it is 7797.36 INR and the overall average income is 9073.35 INR. It indicates that 40.5 per cent of the surveyed households' monthly income is more than the overall average income of ' 9073 in Kanniyakumari, while it is only 23 per cent in Tirunelveli district. The Gini coefficient for Kanniyakumari is 0.52 and 0.56 for Tirunelveli. It means that in comparison with Kanniyakumari district, Tirunelveli has more income inequality. The income-wise preference for a medical system in Kanniyakumari district shows that though there is general preference to the Allopathy system of medicine, it is high among the high income groups. Out of the 23 respondents with the income of more than 17000 INR, 21 (91.3\%) prefer the Allopathic system of medicine. Of the remaining 177 respondents with less than 17000 INR, 122 (68.93\%) persons prefer the Allopathic system of medicine. As far as the health providers are concerned, there is strong preference for private healthcare providers. Of the 200 persons surveyed, 127 persons prefer private healthcare institutions to public healthcare institutions. Income-wise distribution of the respondents shows that rich people prefer private healthcare providers while poor people prefer public healthcare providers. Of the 23 respondents with more than 17000 INR, only two $(8.70 \%)$ prefer public institutions. On the other hand, of the 177 respondents with less than 17000 INR, $71(40.11 \%)$ prefer public healthcare. 
TABLE - 5: Incomewise Distribution of the Respondents and Their Utilization in Tirunelveli

\begin{tabular}{|c|c|c|c|c|c|c|}
\hline $\begin{array}{l}\text { Services } \\
\text { Income (in INR) }\end{array}$ & Allopathy & Traditional & Total & Public & Private & Total \\
\hline$\leq 3000$ & 12 & 2 & 14 & 11 & 3 & 14 \\
\hline $3001-5000$ & 22 & 7 & 29 & 15 & 14 & 29 \\
\hline $5001-7000$ & 52 & 19 & 71 & 37 & 34 & 71 \\
\hline $7001-9000$ & 34 & 6 & 40 & 19 & 21 & 40 \\
\hline $9001-11000$ & 15 & 3 & 18 & 5 & 13 & 18 \\
\hline $11001-13000$ & 10 & 3 & 13 & 2 & 11 & 13 \\
\hline $13001-15000$ & 8 & 1 & 9 & 1 & 8 & 9 \\
\hline $15001-17000$ & 0 & 1 & 1 & 0 & 1 & 1 \\
\hline 17001-19000 & 1 & 0 & 1 & 0 & 1 & 1 \\
\hline 19001-21000 & 0 & 1 & 1 & 0 & 1 & 1 \\
\hline 21001-23000 & 0 & 1 & 1 & 0 & 1 & 1 \\
\hline$\geq 23001$ & 0 & 2 & 2 & 0 & 2 & 2 \\
\hline Total & 154 & 46 & 200 & 90 & 110 & 200 \\
\hline
\end{tabular}

Source: Primary Data

In Tirunelveli district, the Traditional system of medicine is not so popular and so the utilization is also very limited. The number of respondents in the low income group is higher and in the high income group, it is lower in Tirunelveli district in comparison with Kanniyakumari district. Hence, in Tirunelveli, more number of persons utilizes public hospitals than in Kanniyakumari. Of the 200 persons surveyed, 90 families prefer private healthcare institutions to public healthcare institutions in Tirunelveli against only 73 in Kanniyakumari. Specifically speaking, rich people utilize more of private healthcare providers while poor people utilize more of public healthcare. For example, all the six respondents with more than 15000 INR utilize private healthcare institutions. On the other hand, of the 194 respondents with less than 15000 INR, 94 (53.61\%) prefer public healthcare. It is obvious from the last two tables that people's preference in general is towards private healthcare providers.

\section{Education of the Respondents and the Utilization of Healthcare Systems}

Social status of an individual is decided by many factors, such as education, income, and occupation. Education is universally regarded as an instrument of improving the quality of individuals and polishing the character of oneself. Better the education, greater will be the availability of social and economic opportunities. Education has also some influence on the consumption behaviour of individuals including the demand for healthcare services. The matters available in the following table support the already established fact that higher educational qualification is positively associated with higher demand for healthcare services. People of good educational background are health conscious and so they spend more on healthcare. The educational status of the respondents and their preference for the healthcare systems and healthcare providers are portrayed in table 6 : 
TABLE - 6: Educational Status of the Respondents and Their Utilization in Kanniyakumari

\begin{tabular}{|c|c|c|c|c|c|c|}
\hline Education $\quad$ Category & Allopathy & Traditional & Total & Public & Private & Total \\
\hline Illiterate & 6 & 1 & 7 & 1 & 6 & 7 \\
\hline Primary & 52 & 11 & 63 & 24 & 39 & 63 \\
\hline High School & 53 & 28 & 81 & 30 & 51 & 81 \\
\hline Higher Secondary & 18 & 11 & 29 & 14 & 15 & 29 \\
\hline Graduate & 5 & 1 & 6 & 1 & 5 & 6 \\
\hline Professional & 5 & 4 & 9 & 1 & 8 & 9 \\
\hline Technical & 4 & 1 & 5 & 2 & 3 & 5 \\
\hline Total & 143 & 57 & 200 & 73 & 127 & 200 \\
\hline
\end{tabular}

Source: Primary Data

The above table projects that in Kanniyakumari district the preference for a particular healthcare system is not associated with their educational qualifications. Of the nine respondents with professional qualification, five take Allopathy medicine while four prefer Traditional medicine. There are 29 persons with higher secondary qualification. Of them, 18 prefer Allopathy and the remaining make use of the Traditional system. On the other hand, highly qualified persons prefer private healthcare providers to public healthcare providers. For example there are six graduates and nine professionals. Of them only two, one from each group, prefer public hospitals and the remaining 13 prefer private hospitals. In Tirunelveli also highly qualified persons prefer the private sector to the public sector but they prefer Traditional system of medicine to the modern system of medicine. Of the nine graduates or professionals or technicians seven (78\%) prefer the Indian medicine and eight $(89 \%)$ prefer private healthcare institutions. It means that in Tirunelveli, highly qualified persons are well aware of the standout features of the Traditional system. The respondents' preference related to Tirunelveli district according to their qualification is illustrated in table 7 :

TABLE - 7: Educational Status of the Respondents and Their Utilization in Tirunelveli

\begin{tabular}{|c|c|c|c|c|c|c|}
\hline Education & Allopathy & Traditional & Total & Public & Private & Total \\
\hline Illiterate & 24 & 6 & 30 & 18 & 12 & 30 \\
\hline Primary & 77 & 22 & 99 & 46 & 53 & 99 \\
\hline High School & 44 & 10 & 54 & 22 & 32 & 54 \\
\hline Higher Secondary & 7 & 1 & 8 & 3 & 5 & 8 \\
\hline Graduate & 2 & 3 & 5 & 1 & 4 & 5 \\
\hline Professional & 0 & 3 & 3 & 0 & 3 & 3 \\
\hline Technical & 0 & 1 & 1 & 0 & 1 & 1 \\
\hline Total & 154 & 46 & 200 & 90 & 110 & 200 \\
\hline
\end{tabular}

Source: Primary Data

There is negative relation between income and the preference for the Traditional system (- 0.14, which is significant at 5\% level) and income and the preference for the public healthcare institutions (- 0.20, which is significant at $1 \%$ level). However, correlation between Traditional and education is 0.12 [insignificant] and between public hospitals and education is 0.025,[insignificant] in Kanniyakumari district. The different values for Tirunelveli districts, which are: $-0.16,-0.28,0.18$ and -0.19 , are significant at $1 \%$ level. It means that the second hypothesis that 'income has no role to play in the preference for a healthcare system and a 
healthcare provider is rejected and the third hypothesis that 'preference for a healthcare system and a healthcare provider is not influenced by education' is rejected for Tirunelveli but accepted for Kanniyakumari district. To understand the contribution of each factor, multiple regression models are constructed and presented below for the two districts separately.

The multiple regression equations formed for Kanniyakumari district for the preference for the system of medicine is given below:

$P=f\left(X_{1} X_{2}\right), P=$ Preference, $X_{1}=$ Education, $X_{2}=$ Income,

$P_{(A)}=0.24^{*}+0.14^{* *} X_{1}-0.17^{*} X_{2} \quad R^{2}=0.042^{*}, F=4.31^{*}$

$\mathrm{P}_{(\mathrm{P})}=0.50^{*}+0.00^{\mathrm{NS}} \mathrm{X}_{1}-0.20^{*} \mathrm{X}_{2} \quad \mathrm{R}^{2}=0.04^{* *}, \mathrm{~F}=4.00^{* *}$

The details for Tirunelveli district are given below:.

$P_{(A)}=0.02^{N S}+0.14^{N S} X_{1}-0.11^{\text {NS }} X_{2} \quad R^{2}=0.043^{*}, F=4.42^{*}$

$\mathrm{P}_{(\mathrm{P})}=0.75^{*}+0.10^{\mathrm{NS}} \mathrm{X}_{1}-0.24^{*} \mathrm{X}_{2} \quad \mathrm{R}^{2}=0.08^{*}, \mathrm{~F}=9.05^{*}$

$\mathrm{P}_{(\mathrm{A})}=$ Preference for Allopathy, $\mathrm{P}_{(\mathrm{P})}=$ Preference for Public hospitals

$*=$ significant at $1 \%$ level ${ }^{* *}=$ Significant at $5 \%$ level \& NS= not significant.

All the calculated $\mathrm{R}^{2}$ values are significant, but in percentage term all are very small; only four to eight per cent. It means that the identified factors' contribution is very small and so there are some other reasons that influence the usage of healthcare systems and providers.

\section{Other Reasons for Utilizing a Particular System}

Apart from income and education, there are some other reasons to utilize a particular type of medicine or hospital. The various other reasons for using the modern or the Traditional medical care system as indicated by the respondents are presented in tables 8 and 9. However, fast relief is the major reason for utilizing Allopathy medicine and the important reason for utilizing the Traditional healthcare systems is zero side effects. No one reports that the modern medicine is cheap but two respondents report that the Indian medicine is cheap.

TABLE - 8: Reasons for Preferring Modern Healthcare Systems

\begin{tabular}{|l|c|c|}
\hline \multirow{2}{*}{ Reasons } & \multicolumn{2}{|c|}{ Respondents } \\
\cline { 2 - 3 } Fast Relief & Kanniyakumari & Tirunelveli \\
\hline Nearby & 74 & 87 \\
\hline No Diet Restriction & 15 & 23 \\
\hline Neat and Clean & 6 & 5 \\
\hline Care with Patience & 3 & 2 \\
\hline Fast Relief and Nearby & 2 & 3 \\
\hline Nearby and Neat and Clean & 18 & 23 \\
\hline Fast Relief and Care with Patience & 5 & 6 \\
\hline \multicolumn{1}{|c|}{ Total } & 4 & 154 \\
\hline
\end{tabular}

Source: Primary Data 
TABLE - 9: Reasons for Preferring Traditional Healthcare Systems

\begin{tabular}{|l|c|c|}
\hline \multirow{2}{*}{ Reasons } & \multicolumn{2}{|c|}{ Respondents } \\
\hline No Side-effects & Kanniyakumari & Tirunelveli \\
\cline { 2 - 3 } Nearby & 30 & 26 \\
\hline Fast Relief & 1 & 0 \\
\hline Low Cost & 3 & 8 \\
\hline Fast Relief, No Side-effects & 0 & 2 \\
\hline No Side-effects, Nearby \& Low Cost & 12 & 0 \\
\hline Fast Relief, No Side-effects, \& Nearby & 3 & 0 \\
\hline \multicolumn{1}{|c|}{ Total } & 57 & 46 \\
\hline
\end{tabular}

Source: Primary Data

\section{Utilization Of Public Healthcare}

In the public healthcare centres, treatment is available free of cost and so usually the poor and the marginalised make use of these centres. The other reasons for preferring public hospitals are listed out in table 10. Among the other reasons, free of cost is the dominant reason.

TABLE - 10: Reasons for Utilizing Public Healthcare Systems

\begin{tabular}{|l|c|c|}
\hline \multirow{2}{*}{ Reasons } & \multicolumn{2}{c|}{ Ristricts } \\
\cline { 2 - 3 } & Kanniyakumari & Tirunelveli \\
\hline Free of Cost & 29 & 60 \\
\hline Care with Patience & 4 & 0 \\
\hline Nearby & 3 & 4 \\
\hline Fast Relief & 0 & 1 \\
\hline Free of Cost \& No Diet Restriction & 14 & 7 \\
\hline Free \& Care with Patience & 9 & 6 \\
\hline Free and Nearby & 6 & 3 \\
\hline Free of Cost \& for Poisonous Infections & 2 & 4 \\
\hline Nearby \& No Diet Restriction & 2 & 1 \\
\hline Free, Care with Patience and Fast Relief & 2 & 4 \\
\hline Care with Patience \& No Diet Restriction & 1 & 0 \\
\hline Free, Care with Patience \& Nearby & 1 & 0 \\
\hline Total & 73 & 90 \\
\hline
\end{tabular}

Source: Primary Data

\section{Reasons for Utilizing Private Healthcare}

Poor people prefer public healthcare while rich people prefer private healthcare. It means that income is the deciding factor in the preference of healthcare providers. However among the 
other reasons for utilizing private healthcare institutions in both the districts is that in private hospitals, patients are given utmost care. The details are presented in table 11:

TABLE - 11: Reasons for Utilizing Private Healthcare Institutions

\begin{tabular}{|l|c|c|}
\hline \multirow{2}{*}{ Reasons } & \multicolumn{2}{|c|}{ Respondents } \\
\cline { 2 - 3 } Fast Cure & Kanniyakumari & Tirunelveli \\
\hline Care with Patience & 13 & 10 \\
\hline Nearby & 49 & 33 \\
\hline Non-availability of Others/ Medicines & 18 & 11 \\
\hline Neat \& Clean & 3 & 11 \\
\hline Fast cure \& Care with Patience & 1 & 3 \\
\hline Fast cure \& Nearby & 18 & 14 \\
\hline Care with Patience \& Nearby & 3 & 5 \\
\hline Care with Patience, Neat \& Clean & 2 & 7 \\
\hline Nearby \& Convenient & 9 & 10 \\
\hline Nearby \& Neat and Clean & 4 & 2 \\
\hline Fast cure, Care with Patience \& Nearby & 1 & 3 \\
\hline Fast Cure \& Neat and Clean & 2 & 1 \\
\hline Total & 4 & 110 \\
\hline
\end{tabular}

Source: Primary Data

Distance and Usage of a Particular System of Health Care

Accessibility of healthcare facility is an important factor in availing it. People usually make use of the sources of medical care which are available very near to them as travelling to a distant place consumes not only money and time but also creates unnecessary tension. However, there are individuals, who prefer to visit a particular medical care centre though it is located at a distance, if they feel that the treatment provided in that centre is good. Hence, information about the distance to the medical care institution that they usually visit has been collected from the respondents. The details of distance in the selected four taluks of each district are presented in tables 12 and 13: 
TABLE - 12: Distancewise Utilization of Healthcare Systems

\begin{tabular}{|c|c|c|c|c|c|c|c|}
\hline \multicolumn{2}{|c|}{ Distance (in Km) } & $\mathbf{3 3}$ & $\mathbf{4 - 8}$ & $\mathbf{9 - 1 3}$ & $\mathbf{1 4 - 1 8}$ & $\mathbf{1 9 +}$ & Total \\
\hline \multirow{4}{*}{$\begin{array}{c}\text { Kanniyakumar } \\
\text { i }\end{array}$} & Allopathy & 17 & 75 & 28 & 22 & 1 & 143 \\
\cline { 2 - 8 } & Indian & 14 & 25 & 14 & 4 & 0 & 57 \\
\cline { 2 - 8 } & Total & 31 & 100 & 42 & 26 & 1 & 200 \\
\hline \multirow{3}{*}{ Tirunelveli } & Allopathy & 64 & 69 & 8 & 10 & 3 & 154 \\
\cline { 2 - 9 } & Indian & 15 & 17 & 6 & 7 & 1 & 46 \\
\cline { 2 - 9 } & Total & 79 & 86 & 14 & 17 & 4 & 200 \\
\hline \multicolumn{2}{|c|}{ Grand Total } & 110 & 186 & 56 & 43 & 5 & 400 \\
\hline
\end{tabular}

Source: Primary Data

Table - 13: Distancewise Utilization of Healthcare Providers

\begin{tabular}{|c|c|c|c|c|c|c|c|}
\hline \multicolumn{2}{|c|}{ Distance (in Km) } & $\leq 3$ & $4-8$ & $9-13$ & $14-18$ & $19+$ & Total \\
\hline \multirow{3}{*}{ Kanniyakumari } & Public & 11 & 38 & 18 & 6 & 0 & 73 \\
\hline & Private & 20 & 62 & 27 & 15 & 1 & 127 \\
\hline & Total & 31 & 100 & 42 & 26 & 1 & 200 \\
\hline \multirow{3}{*}{ Tirunelveli } & Public & 39 & 36 & 7 & 8 & 0 & 90 \\
\hline & Private & 40 & 50 & 7 & 9 & 4 & 110 \\
\hline & Total & 79 & 86 & 14 & 17 & 4 & 200 \\
\hline \multicolumn{2}{|c|}{ Total } & 110 & 186 & 59 & 43 & 5 & 400 \\
\hline
\end{tabular}

Source: Primary Data

It is obvious from the above tables that nearly 71.50 per cent of the respondents from Kanniyakumari and 77 per cent from Tirunelveli district have made use of modern medicine and the remaining have used Traditional medicine. In Kanniyakumari district nearly 64 per cent of the respondents have preference for private health care providers, while in Tirunelveli district it is only 55 per cent. In Kanniyakumari district, on an average, a public health care centre is available within four kilometres and a private clinic is available within three kilometres and in Tirunelveli district, the respective distances are 5 and 4.67 kilometres. However a few respondents make use of a distant centre as they feel that the treatment given in that centre is good. In some areas, people have visited public hospitals even though they are far away. In Agasteeswaram taluk, six households have made use of public hospitals though they are $14-18 \mathrm{~km}$ away. On the other hand, out of 15 respondents having public hospitals with a distance less than three kilometres, only seven have made use of public healthcare. In Kalkulam taluk, no one has made use of public hospitals though a public hospital is available within three kilometres. In Vilavancode taluk, two households have public hospitals within three kilo meters, but both did not use the service of the public hospitals. The average distance travelled by the respondents in taking medical treatment is calculated. It is a maximum of $10.94 \mathrm{~km}$ in Vilavancode taluk of Kanniyakumari district, and the minimum distance is $3.14 \mathrm{~km}$ in Alangulam taluk of Tirunelveli district. The overall average distance travelled by the respondents to get healthcare in Kanniyakumari is $7.68 \mathrm{~km}$ while it is only $6.04 \mathrm{~km}$ in Tirunelveli. It means that people are ready to travel even distant places where quality medical 
care is available. Hence, the fourth hypothesis that 'the usage of a healthcare provider is not influenced by the distance of a healthcare institution' is accepted.

The main reason for not preferring public sector hospitals, where medical care is provided free of cost, is the indifferent attitude of healthcare professionals. Public sector medical professionals are neither willing to work in rural areas nor do have enough time to heed to the patients' problems. In many health centres there is paucity of manpower and facilities. In India, public health is one of the most neglected sectors, particularly in rural areas. The healthcare services in rural areas are very low and even this meagre healthcare service is not available in remote rural areas.

In India as on the $31^{\text {st }}$ of March 2015, the shortfall of sub-centres is 35145, primary health centres (PHC) is 6556 and community health centres (CHC) is 2316. The shortfall of doctors in PHCs is 2225 and that of specialists in CHCs is 17525 . There is also shortfall in health workers, health assistants and nursing staff. The shortfall of female health workers in sub centres (SCs) is 3934 and that of male health workers is 98027 and there are 7335 SCs without female health workers and 72742 SCs without male health workers. The shortfall of female health assistants is 12448 and that of male health assistants is 15513. The shortfall of nursing staff is 12953 . There are 43695 SCs without regular water supply and 39295 SCs without electricity connection. Among the PHCs functioning in India, 1886 have no water supply and 1220 have no power supply. The average number of rural population covered by a SC is as large as 5473, by a PHC is 33323 and by a CHC is 155463 . The average number of villages covered by a SC is 4.21 , by a PHC is 25.61 and by a CHC is 119.50 . The rural area covered by a SC is $20.47 \mathrm{~km}$, by a PHC is $124.63 \mathrm{~km}$ and by a CHC is $581.45 \mathrm{~km}$ (Rural Health Statistics 2014-'15).

The other facilities available are also very limited. It is observed that only 38 per cent of all PHCs have all the critical staff and 34 per cent have facilities for delivery and postnatal care, three per cent have safe abortion facilities, 8 out of 10 have no obstetrician (CEHAT Report in Sharma 2004). Further, on an average day, 40 per cent of primary healthcare workers in India are not at work i.e., absent from work (Goel 2010). Though Tamil Nadu has enough SCs, PHCs and $\mathrm{CHCs}$, there is shortfall of doctors, specialists, health workers and health assistants. There are 961 PHCs without lady doctors. The shortfall of specialists as on the 31 $1^{\text {st }}$ of March 2015 is 1540, i.e., all specialist posts are vacant since 2012. The shortfall of female health workers is 1030, male health workers 6422, female health assistants 515 and there are 1912 SCs without male health workers. The average rural population covered by a SC is 4276 , by a PHC is 27195 and by a CHC is 96700 .

\section{Suggestions}

If proper awareness is created among people about the standout features of the Traditional system of medicine and if due government support is provided to both the Traditional system and public healthcare providers, then they will recover from all their illnesses and help all sections of people to avail all the needed healthcare facilities. Following policy implications may set right the lacunae existing in the Indian healthcare system and in the public healthcare sector.

The Traditional medicine is preferred for its zero/low side effect. A medicine with low side effect should be preferred to medicines of high side effect if there is no difference of cost, but only by a few households utilized it. As discussed earlier comparatively it is more popular in Kanniyakumari district than in Tirunelveli district as the former has more number of healthcare centres of the Traditional system. Hence, steps should be taken not only to start more healthcare centres of the Traditional system or to make available Traditional medicines in every public sector healthcare centres but also to popularise it among people. As the present government is 
taking steps to popularise yoga, it is gaining importance throughout the world. In this way, other Traditional systems treatment should be popularised.

Even though medical treatment is free in government hospitals, people utilize more of private hospitals than the public hospitals. The main reason for not preferring them is that there patients are poorly treated. In other words, people are reluctant to go to public hospitals due to lack of care and due to the lethargic attitude of health workers. Further, rural people are not well educated to read prescriptions and names of medicines. The details of treatment and the means of taking of medicines are not properly informed in public hospitals whereas all these are very specific in private hospitals. In the dog-eat-dog world, everyone is for making money. Health workers serving in government hospitals are also no exception to this. But healthcare requires selfless, devoted, service minded and sincere persons. Hence, there is a necessity to train them in such a way that they feel that they are the people to serve the society. It is necessary to treat patients with utmost care and patience.

Another reason for not utilizing public hospitals is that the facilities available there are not up to the mark. Rural people have no hardship in getting healthcare services, if enough facilities are available there. However, in India, public healthcare sector is the most neglected one and is in a dilapidated condition. In many PHCs, the facilities available are very limited and there is lack of staff, medicines, tools and equipments, wards, beds and even water and electricity. This is one of the reasons why people do not prefer government hospitals. Steps should be taken to change this situation

As discussed earlier, many posts including those of general doctors and specialists are vacant in public hospitals. The number of created post is low in comparison with the world's average and even the created posts are not filled in. The WHO norm is 23 health workers per 10000 persons. Hence, it is of utmost necessity to improve the availability of human resources such as doctors, CHWs or ASHAs, BRHCs (Bachelor of Rural Healthcare) nursing staff. Today the doctor population ratio is only $0.5: 1000$ and this should be increased to 1:1000. In the same way nurses, ASHAs and other health workers should also be increased. For that many medical colleges and other training institutes should be initiated and steps should be taken to start these institutions in areas where it is of utmost necessity. There are wide disparities in the availability of medical institutions. For example, the medical college population ratio is 1:11.5 million in Bihar while it is only 1:1.5 million in Karnataka and Kerala. This disparity should be levelled by following suitable policies.

The reason for non-availability of facilities in public hospitals is less allotment of fund to public healthcare sector. The public expenditure on health sector should be enhanced to 2.5 per cent of GDP before the end of the $12^{\text {th }}$ plan. At present it is only 1.09 per cent. In due course it should be increased to at least 5 per cent; it is 17 per cent in the USA. This may reduce considerably the out-of-pocket spending on healthcare from the present level of 67 per cent and bring down impoverishment of households.

Primary health centres are the main sources of getting free medical treatment and so every facility required by rural people should be there. Hence, the allotment of funds to PHCs should be enhanced to at least 70 per cent of the total healthcare expenditures. Though primary healthcare is the backbone of the public healthcare system, the secondary and tertiary care should not be neglected. Hence, the secondary and tertiary care should be strengthened and steps should be taken to increase the bed capacity to at least 2 functional beds per 1000 population. The global average of beds is 2.9 per 1000 population.

There is wide disparity between rural areas and urban areas in the availability of healthcare facilities. Majority of the population lives in rural areas but only meagre health services are 
available there. In the study area also there are few healthcare centres and people have to travel a long distance to visit a good healthcare centre. This problem should also be rectified. To attain equality among areas, the state has to transfer resources according to the requirements.

The efficiency of the working of public healthcare sector is low and the quality of healthcare services available in public hospitals is very poor. To attain efficiency and quality, the attitude of healthcare providers should be changed and they should be patient-friendly. Poor patients approach public hospitals only due to their financial inability, but the unfavourable situations in public hospitals force them to knock the door of private hospitals.

It is reported by many health economists that contractors are more effective in delivering quality care and in the coverage of services than the existing government system. Contracting for health service delivery has a number of attractive features; focusing on results, flexible, less corruption, constructive competition, improved absorptive capacity, better distribution of health workers, and managerial autonomy. It is believed that contracting with nongovernmental organisations or other non-public entities improves both coverage and quality of care. If possible, health services can be provided through contract system. In improving healthcare facilities public-private partnership can be encouraged.

From all the discussions carried out above, it is clear that the Indian system of medicine is not being utilised like Allopathy and people are reluctant to visit public sector hospitals. Getting treatment in private healthcare institutions leads to very high out-of-pocket expenditure and impoverishment of families. It may reduce the consumption of healthcare services. Less healthcare service usage may have its own impact on the health of people. Quality healthcare should be made available to all, irrespective of economic and educational status, caste, religion and area. Then the proverb 'Health is Wealth' will have the real meaning.

\section{References}

Acharya, Akash., and Kent Ranson. M. (2005): Health care Financing for the Poor Communitybased Health Insurance Schemes in Gujarat. Economic and Political Weekly, XL (38), Sep. 17-23, 441-450.

Anbumani, R (2004): "Public Health will be part of School Syllabus", The Hindu, 24 ${ }^{\text {th }}$ October, $p$ 4 .

Banerjee, Abhijit., Deaton, Anugus., Duflo, Esther. (2004): Health care Delivery in Rural Rajasthan. Economic and Political Weekly, XXXIX (9), February, 28.

Bansod., Dhananjay W., and Sarang P. Pedgaonkar. (2014): Health Equity in Public Health, Yojana, February, 35-43.

Baru, Rama., Arnab Acharya., Sanghmitra Acharya., Shiva Kumar A.K., Nagaraj, K. (2010): Inequities in Access to Health services in India. Caste, Class and Region. Economic and Political Weekly, XLV (38), Sep 18, 49-58.

Baru, V. Rana., Q. Imrana and P. Ritu., (2000): Medical Industry. Illusion of Quality at what cost. Economic and Political Weekly, June 15, 2509-2511.

Chatterjee, Biswajit. (2009): Globalisation and Health Sector in India. New Delhi: Deep \& Deep Publication Pvt. Ltd.

Chinai, Rup and Rahul Goswami, (2005): Are we ready for medical tourism? The Hindu Magazine, 17th March.

Goel S. L. (2010): Primary/Rural Health Care System and Hospital Administration. New Delhi: Deep \& Deep Publication Pvt. Ltd. Government of India, Rural Health Statistics 2014-'15 \& 2013-'14. 
Husain, Zakir. (2011): Health of the National Rural Health Mission. Economic and Political Weekly, XLVI (4), January 22, 53-60.

Jackson, Timothy Powell., Arnab Acharya., and Anne Mills. (2013): An Assessment of the quality of Primary Health Care in India. Economic and Political Weekly, XLVIII (19), May 11, 5359.

Kanmony, Cyril J. (2009): The Economics of Health Care and Human Rights in India. In Kanmony, Cyril J. (Eds.) (2009). Human Rights and Health care. (pp.63-79). New Delhi. Mittal Publications.

Kishore, J. (2009): National Health Programs of India-National Policies and Legislations Related to Health. New Delhi: Century Publications.

Kuruvilla, M J (2011): "Let us rescue our Healthcare from the Sick Bed", The Hindu, $3^{\text {rd }}$ July, p 12.

Loevinsohn, Benjamin. (2008): Performance-based Contracting for Health Services in Developing Countries. Washington D.C: The World Bank.

Meeta and Rajivlochan. (2010): Inequities in Health, Agrarian Distress and a Policy of Avoidance. Economic and Political Weekly, XLV (43), October 23, 41-47.

Murthy, G, R. K. (2006): Health care Insurance. In Lahiri, Keka. (Eds.), Global Health Care Management. (pp.101-111). Agartala: The ICFAI University Press.

Nagpal, Somil. (2014): Financing India's Quest for Universal Health Coverage. Yojana, February, 4-9.

Nagulapalli, Srikant (2014): Burden of Out-of-Pocket Health Payments in Andhra Pradesh, Economic and Political Weekly, XLIX,42, October 18, 64-72.

Nandraj, Sunil. (2012): Unregulated and Unaccountable, Private Health Providers. Economic and Political Weekly, XLVII (4), January 28, 12-17.

Perker, Alexander. S. (2005): Managing Scarcity through Strategic Purchasing of Health Care. In Perker, Alexander. S., and John C. Langenbrunner. (Eds.), Spending Wisely. (pp.23-39). Washington D.C: The World Bank.

Prasad, G. Monikanda., and Cyril Kanmony J. (2010): Traditional Medical Care System in India. In Kumar, J. C Jaisingh Vasantha., J. Cyril Kanmony., M. Jezer Jebanesan., D. Peter. (Eds.), Global and Regional Economic Issues. (pp. 31-38). Kanniyakumari: Pooja Publishers.

Prasad, Purendra N and Raghavendra P. (2012): Health care Models in the Era of Medical NeoLiberalism, Economic and Political Weekly, XLVII (43), October 27, 118-126.

Prinja, Shankar. (2014): Health and Development, Yojana, February, 44-49.

Prohit, Brijesh C. (2010:. Efficiency Variation at the Sub-State Level-The Health care System in Karnataka. Economic and Political Weekly, XLV (19), May 8.

Rajagopal, Santhosh. (2004): A Vision for the Public Health Sector, The Hindu, 30th March.

Reddy, Padmanabh. M. (2012): In Pursuit of an Effective UHC. Economic and Political Weekly, XLVII (8), February 25, 74-76.

Sakthivel, Selvaraj, Habib Hasan, Maulik Chokshi, Anit Sengupta, Amitava Guha, Mira Siva, S Srinivasan, Anant Phadka, K M Gopakumar, M R Santhosh, Leena Menghaney, and Kajal 
Bhardwaj (2012): "Pharmaceutical Pricing Policy: A Critique", Economic and Political Weekly, XLVII, 4, January 28, pp $20-23$.

Sangole, Sanjay (2003): "Primary Healthcare in Disadvantaged Urban Areas" Employment News, April, 5-11.

Sharma, Kalpana (2004): “How Healthy is our System?" The Hindu, $8^{\text {th }}$ June.

Sundararaman, T; Indrani Mukhopadhyay, and V. R. Muraleedharan (2016): “No Respite for Public Health", Economic and Political Weekly, LI (16), April 16, pp $39-42$.

Varshney, Vibha., and Aparna Pallavi. (2011): Unhealthy Countryside, Down to Earth, April 16, 26-29. 